\title{
Ciudad compacta versus ciudad difusa. Caso de estudio: Valencia, ciudad continua.
}

\author{
Iñigo Magro de Orbe \\ Departamento de Proyectos Arquitectónicos, Universidad Politécnica de Valencia, Valencia, España. \\ E-mail: igmagdeo@pra.upv.es, inigomagro@vmc35.com
}

\begin{abstract}
Resumen. Valencia es un "palimpsesto". Desde su fundación romana hasta nuestros dias, ha sabido desarrollarse continuando las huellas de su trazado histórico. Desde aquellos versos de Machado: "Valencia de finas torres..." -que evocaban el perfil de la ciudad representada en los grabados del XVIII-, hasta las esbeltas torres que Jean Nouvel propuso en la "desembocadura verde" del antiguo cauce del Turia, Valencia ha sabido mantener la continuidad de las trazas de su ciudad histórica. A su vez, la huella del viejo cauce ha sido el vehiculo que ha intentado conectar definitivamente la ciudad intramuros (dibujada por Tosca en 1704), con el mar Mediterráneo. En ese sentido, el antiguo cauce del río, cuyo curso fue desviado tras la riada de 1957, será el pretexto para indagar en la continuidad que se propone. Aceptando la huella del cauce en su condición actual, queremos aprovechar la oportunidad que supuso su desvio indagando estrategias proyectuales en las que la historia de los distintos lugares por los que discurre irá "contaminando" su trazado. La dimensión urbana de la arquitectura, en los episodios de ocupación del viejo cauce, será considerada como material de proyecto y actuará como nexo entre la memoria y el deseo. Frente a planteamientos de análisis puntuales, que favorecerían la discontinuidad, proponemos un relato continuo de los acontecimientos que han ido dejando huellas imborrables en el trazado urbano. El proyecto de arquitectura será el vehículo que nos acompañará en ese recorrido histórico convirtiéndose en el autentico mediador entre la historia y el futuro de la ciudad. Porque, como dice el profesor J.L.Trillo*: “... la Ciudad Continua continúa siendo el objeto principal e ineludible de nuestra referencia arquitectónica".
\end{abstract}

Palabras clave: Trazas, huellas, cauce del Turia, proyecto, continuidad.

\section{Antecedentes históricos}

Valencia es una "ciudad continua" que ha pasado por diferentes periodos históricos que han ido dejando huellas en la construcción de su estructura urbana.

Desde sus orígenes fundacionales romanos (138 a. C), la ciudad se ha ido desarrollando en anillos concéntricos que se han expandido hacia el sur ante la imposibilidad de superar la barrera física del río Turia por el norte. Las murallas romanas, las árabes y finalmente las murallas cristianas, definieron una ciudad encerrada en sus propios límites sin posibilidad de apertura hacia el exterior $\mathrm{y}$, desde luego, sin posibilidad de conectar con el mar.

El río Turia, sin embargo, ha estado siempre ligado a la deseada conexión de Valencia con el mar Mediterráneo.

Dadoelcaráctertorrencialdelrío-queprovocó gran cantidad de inundaciones periódicas a lo largo de su historia (22 desbordamientos y 11 crecidas entre 1321 y 1957) y que acabaron por provocar fuertes alteraciones y aterramientos en su desembocadura-, se tuvieron que realizar distintas obras de acondicionamiento y mejora

http://dx.doi.org/10.4995/ISUFh2019.2019.9554

(cc) EY-NC-ND 2019, Editorial Universitat Politècnica de València 
que influyeron en la estructura geográfica del delta portuario. En ese sentido, hay que recordar que el primer dique de contención en la dársena del río Turia (varadero para embarcaciones) se realizó en 1686, y que las primeras obras de mejora del puerto no se llevaron a cabo hasta el año $1792 \ldots$

Sin embargo, la deseada vinculación de la ciudad histórica de Valencia con el Mediterráneo no empezó a materializarse hasta el siglo XIX, cuando, en 1802, se realizó la apertura del Camino del Grao (actual Avenida del Puerto), una vía urbana de $3 \mathrm{~km}$ de longitud que, por primera vez, dejaba conectada físicamente la ciudad con los Poblados Marítimos y con el puerto de Valencia.

A partir de 1837, los Poblados Marítimos se fueron consolidando en torno a las trazas de las cuatro acequias que desembocaban en el mar (Rivet, d'En Gash, Pixavaques y La Cadena), marcando los límites de los tres barrios marineros. Efectivamente, desde El Grao, propiamente dicho, $\mathrm{y}$ en dirección Norte, se fueron asentando los poblados de Canyamelar, Cabanyal y Cap de França, separados por las trazas de las mencionadas acequias dando lugar a una peculiar estructura urbana que ha mantenido su continuidad hasta la actualidad.

Los Poblados Marítimos se convirtieron, de hecho, en la primera referencia de la vocación marinera de los valencianos expresada, entonces, a través de aquellos pequeños núcleos urbanos de origen humilde, cuyos habitantes fueron construyendo sus cabañas y barracas junto a la playa.

Por otra parte, las obras de mejora en el puerto y la construcción de la dársena interior (1869) juntamente con la anexión definitiva a Valencia de los Poblados en 1897, potenciaron el acercamiento de Valencia al mar, dejando abierta la posibilidad de un gran proyecto urbanístico que la conectara definitivamente con el Mediterráneo a través de su Frente Litoral.

Como es lógico, esa posibilidad abrió muchas expectativas de crecimiento y desarrollo que fueron aprovechadas por las clases sociales más favorecidas para alimentar sus ensoñaciones marineras. Sin embargo, estas expectativas no tuvieron posibilidades reales de realizarse hasta mediados del siglo XX cuando, debido al desbordamiento del Turia en 1957, se procedió al desvío de su cauce dejando liberado su viejo trazado para potenciales usos urbanos al servicio de todos los valencianos.

\section{Desde el siglo XVIII al XXI: Relato de una oportunidad}

Valencia ha sido una ciudad más fluvial que marítima debido a que su origen en la llanura aluvial del río Turia la ha mantenido alejada varios kilómetros de la costa. Sin embargo, ha sabido reconocer las huellas de su estructura urbana precisamente por su particular relación con el río y con el mar.

Por una parte, el viejo cauce del Turia ha sido un elemento estructurante que ha permanecido anclado en la imagen de la ciudad desde sus orígenes fundacionales. Por otra, la vocación marinera de la ciudad se ha visto potenciada, como ya hemos dicho anteriormente, a partir de la liberación del cauce de sus funciones fluviales para convertirse en el autentico "cordón umbilical" que ha sabido mantener intactas esas expectativa de apertura al mar.

\section{Siglo XVIII}

Para entender la peculiar estructura urbana de la ciudad de Valencia y su relación con el río, tendríamos que remontarnos al plano de la ciudad dibujado por el padre Tosca en 1704.

Efectivamente, cuando Tosca dibujó el plano de la ciudad (Valentia Edetanorum), el trazado del Turia marcaba, juntamente con las murallas cristianas, los límites de la ciudad histórica. La ciudad aparecía encerrada dentro de sus murallas dejando el cauce del río, por el norte, como la única posibilidad de conexión con el mar a través de su desembocadura en el Mediterráneo.

Por otra parte, el trazado urbano de la ciudad con sus calles y sus monumentos dibujados por Tosca en el XVIII, ha permanecido prácticamente intacto hasta la actualidad poniendo de manifiesto su continuidad porque, como sostiene el profesor Juan Luis Trillo, la estabilidad formal de las ciudades históricas estaría garantizada por la permanencia de sus parcelarios y sus trazados viarios a pesar de la constante sustitución y modernización de sus 
edificios. En ese sentido, quiero resaltar que aquellos valores formales, dibujados por Tosca, han permanecido anclados a los muros de sus construcciones, a los trazados de sus calles y, por supuesto, a su cultura y a su historia.

Esa ciudad encapsulada, sin posibilidad de crecimiento más allá de sus propios límites -cuya imagen dieciochesca quedó definitivamente sintetizada en algunos grabados del siglo XVIII con su perfil (de torres y campanarios) emergiendo sobre las murallas-, fue glosada por Antonio Machado en sus conocidos versos: "Valencia de finas torres y suaves noches..." que ponían de manifiesto la sensibilidad del poeta para definir esos valores formales que han permanecido intactos a través de su historia.

\section{Siglo XIX}

Sin duda, el derribo definitivo de las murallas cristianas en 1865, que encorsetaban el casco histórico de Valencia impidiendo su expansión, supuso un punto de inflexión en el desarrollo urbano de la ciudad.

Quiero recordar que tan solo unos años antes, en 1851, se produjo su apertura parcial en el entorno de la c/ Xátiva para posibilitar la salida de la Línea Férrea del Grao -cuya estación central se encontraba intramurosy permitir la conexión de la ciudad con el puerto. Esta línea férrea será muy importante para entender la futura imagen de la ciudad a través de la continuidad de su trazado; porque, efectivamente, la actual Avenida del Antiguo Reino, que se trazó sobre la huella de aquellas vías del ferrocarril portuario, acabaría prolongándose definitivamente hasta el puerto por la actual Avenida de Francia: todo un símbolo de la continuidad de las huellas que la ciudad de Valencia ha ido dejando en sus ansias de conexión con el mar.

Con el derribo de las murallas se abrieron muchas expectativas. Los terrenos liberados sobre las huellas de las antiguas murallas, conformaron las rondas perimetrales que actualmente circunvalan la ciudad histórica y marcaron las directrices para las grandes operaciones urbanísticas previstas para la expansión de la ciudad a través de sus planes de ensanche.

El primer ensanche exterior de la ciudad se produjo en el año 1884 según el proyecto de los arquitectos Calvo, Ferreres y Arnau. Este plan fue definido por el arquitecto Juan Luis Piñón como el primer "anillo de acoplamiento entre la ciudad antigua y la nueva que se desarrollará en el futuro..." Se trataría, según Piñón, de una especie de "plastilina" que se acoplaría perfectamente a las irregularidades de las antiguas murallas cristianas dejando trazados, a su vez, dos ejes perpendiculares (las actuales grandes vías) que servirían al arquitecto Francisco Mora como referente geométrico para planificar el segundo ensanche de la ciudad en 1907.

\section{Siglo XX}

El inicio del siglo XX estuvo marcado por las reformas arquitectónicas realizadas en el nuevo centro de la ciudad dirigidas por el arquitecto Francisco Mora Berenguer. En efecto, la demolición del Convento de San Francisco (actual Plaza del Ayuntamiento) en 1891, liberó unos terrenos que acabarían por convertirse en el nuevo centro de Valencia. El nuevo Ayuntamiento, construido por Mora entre 1905 y 1929, juntamente con la remodelación del insalubre Barrio de Pescadores y el traslado de la Estación fuera de las antiguas murallas, fueron algunas de las operaciones que acabarían por redefinir el nuevo centro de la ciudad sobre las huellas del antiguo convento.

Por su parte, el nuevo ensanche de Valencia, proyectado por Francisco Mora en 1907, permitió la expansión de la ciudad por el S-W ampliando los límites propuestos por el primer ensanche hasta dos nuevos ejes perpendiculares y paralelos a los anteriores. De hecho, el título del proyecto del año 1907 decía textualmente: "Proyecto de ensanche de Valencia y ampliación del actual". No se trataba, por tanto, de empezar "ex novo", sino de dar continuidad al crecimiento de la ciudad a partir de los dos ejes perpendiculares previstos en el plan de 1884.

Turia's line: mientras tanto, el río seguía su curso...

Entre los años 1920 y 1949 (año en el que se produjo el primer gran desbordamiento 
del Turia del siglo XX) y a pesar de ser conscientes de sus habituales crecidas, el cauce estuvo "ocupado" por construcciones y chozas autoconstruidas de baja calidad que fueron arrasadas por esta última riada. Por otra parte, los márgenes del canal del río siguieron siendo el lugar de encuentro ciudadano para el desarrollo de diversas actividades lúdicas y comerciales respondiendo a la tradición festiva y de intercambio de los valencianos...

Finalmente, la gran inundación producida en el año 1957 lo precipitó todo y las viejas aspiraciones de recuperar el cauce como espacio público al servicio del esparcimiento y disfrute de los valencianos, se vieron favorecidas por tal tragedia. El desvió del cauce para prevenir futuras y previsibles inundaciones se hizo inevitable....

Si el derribo de las murallas en el XIX supuso un punto de inflexión en la configuración de la Valencia moderna, creo que la gran riada de 1957 y el posterior desvío del cauce del río a la periferia sur, fueron unos acontecimientos fundamentales para seguir alimentando las expectativas de conexión de la ciudad con el mar.

Efectivamente, tras la riada del 57 el "Plan Sur" liberó definitivamente los terrenos del antiguo cauce del río convirtiéndolo en una "anomalía" urbana que, sin embargo, abriría infinidad de oportunidades para la ciudad. Se trataba de un vacío, un surco, que seccionaba la ciudad en sentido W-E y que, en su recorrido sinuoso y lineal, debería de ser sensible a las distintas circunstancias que iría encontrando en su trayectoria. El viejo cauce dejaba abiertas todas las posibilidades, y una gran oportunidad, para convertirse en un espacio urbano continuo con capacidad para conectar las distintas sensibilidades urbanas a lo largo de su recorrido.

Sin embargo, no todas las iniciativas fueron en el mismo sentido: frente a las voces que reivindicaron su uso al servicio del automóvil, permitiendo un entramado de autopistas y vías de comunicación en la cota inferior de la ciudad y, por tanto, alejadas de los verdaderos conflictos urbanos, se alzaron otras que reivindicaron el viejo cauce como un espacio verde, de uso público, que podría acabar por conectar definitivamente la ciudad con el mar
Mediterráneo.

Así, la década de los 70 se convirtió en una etapa de grandes reivindicaciones ciudadanas que bajo el lema "El llit del Turia es nostre y el volem verd", posibilitó que el viejo cauce iniciara su reconversión en un espacio para "disfrute popular..."

Finalmente, las diversas manifestaciones, concursos de arquitectura, exposiciones y movilizaciones ciudadanas, desembocaron en el proyecto de Ricardo Bofill de 1982. Sus planos, maquetas y dibujos fueron expuestos en la Lonja bajo el sugerente título de "El Jardín del Turia" que resumía todas las ilusiones ciudadanas depositadas en el proyecto para el "uso popular y festivo del viejo cauce...

\section{Siglo XXI}

La "Línea del Río" continuó su recorrido hacia el mar a pesar de que el proyecto de Bofill no llegó a materializarse en su totalidad. Sin embargo, el viejo cauce seguía atravesando la ciudad desde el Oeste hasta el Este -desde el Parque de Cabecera hasta Nazaret-, y la ciudad continua continuaba abierta para aprovechar esa gran oportunidad. Aceptando el nuevo carácter urbano del cauce del río, se propuso indagar en las oportunidades que brindaba su desvío. Su carácter continuo y unitario, así como su propiedad especular, abrió inmensas posibilidades encaminadas a asumir las transformaciones experimentadas en el tejido urbano del perímetro de la ciudad histórica y sus posibles relaciones con ese nuevo parque lineal que debería de conectar definitivamente la ciudad con el mar.

En la última década del S.XX y los primeros años del XXI, se produjeron una serie de iniciativas tendentes a intervenir en el cauce y reavivar, así, esa vieja aspiración marinera de los valencianos, aunque, a mi juicio, sin resultados satisfactorios. Intentaré, a continuación, hacer un breve análisis y valoración de algunas de las más significativas.

En 1998 se inauguró el proyecto estrella de la arquitectura valenciana. En efecto, $\mathrm{La}$ Ciudad de las Artes y las Ciencias, diseñada por Santiago Calatrava, fue, sin duda, el proyecto arquitectónico más importante y mediático de finales del siglo anterior. Se trataba, 
sin embargo, de un conjunto de "edificios emblemáticos" (formalistas y desarraigados) que no fueron capaces de vincularse a la ciudad más allá que a través de su propio simbolismo. Los diversos edificios se distribuyeron en el viejo cauce sin apenas haber sido capaces de cualificar los lugares que ocupaban: ni desde sus desmesuradas escalas, ni desde sus formalismos excluyentes. Estaríamos ante uno de los ejemplos más claros de lo que se llamó, no sin razón, la Arquitectura del Espectáculo que, por otra parte, reflejaba la política urbanística llevada a cabo por el Ayuntamiento de Valencia en esos últimos años del pasado siglo.

Por otro lado, y en el contexto mediático de La America's Cup, se llevaron a cabo varias propuestas que, bajo el aparente interés de seguir buscando soluciones para la definitiva apertura de Valencia al mar, fueron utilizadas para promocionar ese gran evento internacional.

Me voy a referir brevemente a dos de las que más repercusión tuvieron en los medios de comunicación: el proyecto "Valencia Litoral" (2004), de Jean Nouvel, y el concurso de ideas "Marina Real Juan Carlos I" (2007), en el ámbito de la Dársena Interior del puerto.

Valencialitoral:un proyectode "aproximaciones sensibles"

El proyecto "Valencia Litoral" fue una iniciativa de promoción privada que apostaba por una intervención global en el frente marítimo. Pretendía "generar una dinámica de dialogo" en determinados espacios del frente litoral para conseguir la "terminación de la ciudad y su conexión definitiva con el mar".

Efectivamente, el proyecto de Nouvel, que contó con la colaboración del arquitecto valenciano J. $\mathrm{M}^{\mathrm{a}}$ Lozano y del sociólogo J. Miguel Iribas, se planteó como una estrategia de trabajo a largo plazo (15-20 años) en la que, por primera vez en la política urbana valenciana, se contempló de forma unitaria el tratamiento del frente litoral de la ciudad: desde Nazaret y La Punta (en el sur), pasando por el puerto y la playa de la Malvarrosa, hasta la Patacona (en el norte).

Jean Nouvel, proponía la conexión con el mar desde el "respeto" a la historia y el carácter de El Cabanyal, con la puesta en valor de las playas de Nazaret y la Malvarrosa, la integración de la huerta en La Punta y la articulación del conjunto con el puerto. Todo ello sin olvidar la importancia del río Turia en su encuentro con el Mediterráneo; en esa zona, Nouvel propuso un gran "delta verde" lleno de vegetación y juegos de agua, de modo que... "el bosque pudiese llegar hasta la playa".

Esta zona de encuentro del río con el mar se reservaría, a su vez, para actividades terciarias rodeadas de vegetación y en donde los esbeltos edificios se plantearían como "agujas que darían ritmo y verticalidad" ganando, de esa forma, el espacio libre necesario para realzar el cauce verde del Turia; río que, el arquitecto francés, llegó a considerar como "una suntuosa anomalía en la ciudad de Valencia".

Fue, por tanto, una propuesta "global, de conjunto" que indagaba en la naturaleza de los barrios, el estuario del río, el puerto, la geografía y la historia de Valencia, para crear un urbanísimo de "aproximaciones sensibles..." capaces de dar continuidad a la historia de la ciudad a través del río y de su desembocadura natural en el Mediterráneo.

Marina Real: un proyecto para La Copa del América

Unos años después y tan solo unos meses antes de la celebración de La America's Cup, el "Consorcio Valencia 2007" (formado por Ayuntamiento, Generalitat, y Gobierno de España), convocó un concurso internacional de arquitectura para buscar soluciones en el ámbito de la Dársena Interior del puerto y sus zonas colindantes.

La convocatoria y las bases del concurso "Marina Real" fueron dadas a conocer en un acto propagandístico celebrado en Venecia presentado por la mismísima alcaldesa de Valencia. Fueron invitados a participar algunos de los arquitectos más mediáticos del momento: Foster, Nouvel, Chipperfield, OMA, von Gerkan (GMP), entre los extranjeros, y, entre los españoles, Ferrater y Peñin que formaron equipo con la prestigiosa firma norteamericana SOM.

El planteamiento del concurso fue, a mi juicio, totalmente desproporcionado, no sólo 
por el nivel de exigencia de la presentación (ocho paneles en formato DIN-A.0) sino también, por la ambigüedad en sus contenidos programáticos y en los propios límites del área de intervención. Parecía como si tan sólo se estuviera buscando la genialidad de alguno de los "arquitectos-estrella" convocados para, con su poder de reclamo mediático, impulsar y garantizar el éxito de la Copa del América...

El jurado, que estuvo presidido por Rita Barberá y contó con la presencia de especialistas internacionales (el brasileño Jaime Lerner, el holandés Donald Lambert, el chino Cuui Kai, la griega Rania Kolutsinioti y la valenciana Arantxa Muñoz), optó por una solución salomónica al otorgar el primer premio "ex aequo" al proyecto presentado por el francés Jean Nouvel, y al realizado por el equipo alemán GMP dirigido por Meinhard von Gerkan.

Ambas soluciones apostaban -desde un riguroso conocimiento del lugar-, por maneras diferentes de entender la ciudad, pero perfectamente coincidentes en su voluntad de continuar transformándola mediante el proyecto arquitectónico.

Nouvel, abordó el problema desde la estrategia global heredada de su anterior proyecto "Valencia Litoral", reproduciendo, de hecho, algunas de sus soluciones. Su proyecto seguía apostando por una "reflexión sobre el concepto global del Litoral de Valencia", en el que adquiría una importancia vital el tratamiento "verde" del río Turia en su encuentro con el mar.

Por su parte, von Gerkan concentró todos sus esfuerzos en una solución plagada de recursos de "manual urbanístico". Si bien es cierto que también proponía una desembocadura "verde" del río, en este caso el protagonismo lo adquiría la rotunda prolongación de la Avenida de Francia -sobre la huella del antiguo trazado ferroviario del Grao-, que se extendía hasta el centro de la dársena, culminándola con dos espectaculares "torres gemelas" de más de 200 metros de altura como reclamo visual del conjunto ordenado...

\section{A modo de epílogo.}

El proyecto "Valencia Litoral" fue presentado al Ayuntamiento en noviembre de 2004 con gran despliegue de medios propagandísticos. Tres años después, en 2007, se presentó el proyecto de la Marina Real (unos días antes de la celebración las regatas de la Copa América). Las regatas tuvieron un éxito sin precedentes, pero tan solo nos dejaron el edificio "Veles e Vents", de David Chipperfield, como referente arquitectónico de calidad. Sin embargo, el sueño de la apertura de Valencia al mar a través de su Frente Litoral continuó abandonado en el baúl de las oportunidades perdidas...

Hoy, con la puesta en marcha del nuevo proyecto arquitectónico para El Cabanyal -superadas las disputas sobre la prolongación de la Avenida de Blasco Ibáñez por el interior de su trama-, aparecen nuevas oportunidades para poder conseguir, al fin, que Valencia se abra definitivamente al mar a través de la regeneración de este barrio marinero. Porque el "barrio vivo del Cabanyal" podría convertirse en el "filtro urbano" por el que discurriría la vida de la ciudad en busca del mar Mediterráneo.

Por otra parte, las reivindicaciones y movilizaciones ciudadanas exigiendo la recuperación de la Punta y del parque de Nazaret, la eliminación de la ZAL y en contra de la ampliación de las zonas portuarias, encaminadas, todas ellas, a conseguir espacios urbanos de uso público al servicio de los ciudadanos -tal y como ya se hizo en los años 70 con el viejo cauce del Turia-, nos animan a mantener viva la esperanza...

En todo caso, estoy seguro de que aquellos versos de Machado evocando la Valencia de "finas torres" del XVIII, podrán permanecer anclados en nuestra memoria al recordar el perfil de los esbeltos edificios que Nouvel propuso en la desembocadura verde del Turia. Porque la historia urbana de Valencia se seguirá construyendo desde la buena arquitectura, entendiendo el papel del proyecto arquitectónico como mediador entre el pasado histórico y el futuro esperanzado de nuestra ciudad; es decir, como la herramienta imprescindible para poder seguir transformando la ciudad continua.

\section{Referencias}

AA.VV. El Ensanche de la ciudad de Valencia 
de 1884. COACV, 1984

De Insausti, Pilar; Llopis, Amando: El Turia y la ciudad de Valencia. Propuestas y Proyectos de utilización del Viejo Cauce como parque urbano 1979-1990. Trabajo de Investigación Inédito. Colegio Oficial de Arquitectos de la Comunidad Valenciana. Demarcación de Valencia. 1981

Magro de Orbe, I. Lacalle, C. García, M. "Turia's Line. Estrategias de regeneración urbana". Taller3. Curso 2016-2017. Edit. UPV

Magro de Orbe, I. Lacalle, C. García, M. "La línea del río. El Turia como pretexto". Taller3. Curso 2017-2018. Edit.UPV

Magro de Orbe, I. Lacalle, C. García, M. "Puerto. Infraestructuras de acogida". Taller3.TdA/TFM. Curso 2017-2018. Edit. UPV

Taberner, F. "Valencia entre el Ensanche y la Reforma Interior". Ed. Alfons el Magnànim. 1987

Trillo, J.L. "Argumentos sobre la contigüidad en la arquitectura". Universidad de Sevilla. 2001

"PASAJES, Arquitectura y Crítica" - 65. "Valencia Litoral, un proyecto de actuación urbana"

Vigil de Insausti, A. "Paisajes fluviales. La ciudad de Valencia y el río Turia. Metodología de intervención en cauces urbanos". (Tesis doctoral. Dir. Pilar de Insausti. UPV, 2012) 